\title{
Anxiolytic-like effect of Pistacia atlantica fruit in intact and gonadectomized rats subjected to chronic stress
}

\author{
Rashidi Sh, $\mathrm{MSc}^{1}$, Askari N, $\mathrm{PhD}^{2 *}$, Abbasnejad M, $\mathrm{PhD}^{3}$ \\ 1- MSc Student, Dept of Physiology, Shahid Bahonar University of Kerman, Kerman, Iran. 2- Assistant Prof., Dept. of \\ Physiology, Shahid Bahonar University of Kerman, Kerman, Iran. 3- Professor, Dept. of Physiology, Shahid Bahonar \\ University of Kerman, Kerman, Iran.
}

\begin{abstract}
Received: November 2015, Accepted: December 2015

Background: Testosterone level in men decreases with aging (andropause) and androgen deficiency is responsible for a variety of behavioral symptoms such as anxiety. The aim of this study was to investigate the effect of Pistacia atlantica (bane) fruit extract on anxiety-like behavior in intact and gonadectomized rats.

Materials and Methods: In this study, adult male rats were divided into two groups of intact and gonadectomized rats. The rats were submitted to a chronic unpredictable stress (CUS) paradigm, and subdivided into treated or nontreated groups $(100 \mathrm{mg} / \mathrm{kg}$ of bane extract orally daily for 20 days). Anxiety-like behavior was evaluated using the elevated plus maze (EPM) test.

Results: Bane treatment increased the percentage of both time spent and entries in the open arms of EPM in intact and gonadectomized rats. Additionally, the effects of chronic stress were reversed by bane treatment; the percentages of entries and time spent in the open arms decreased in intact and gonadectomized chronically stressed rats.
\end{abstract}

Conclusions: These results suggest that $P$. atlantica may have some anxiolytic-like properties in castrated and intact rats.

Keywords: Testosterone, Anxiety, Pistacia, Mastictree.

\section{Introduction}

Testosterone is an important male hormone that is responsible for many functions in the body, and low testosterone can affect physiological and biological functions. Testosterone levels in men begin to decline with aging at a gradual rate from the age of 30 (1). This reduction in testosterone level (andropause) leads to diseases such as diabetes mellitus (2) and coronary atherosclerosis (3). Furthermore, mood changes and difficulties associated with low testosterone include loss of the sense of well-being, irritability, nervousness, mood swings as well as depression and anxiety (4).

Mood and anxiety disorders demonstrate one of the largest health burden on society today; nevertheless, few new therapeutics have appeared in the past two decades. Neuroimaging has indicated disorders in the limbic circuit in combination with the amygdala, prefrontal cortex, and hippocampus (5). Metabolic syndromes may have a correlation with anxiety and depression, but its nature is unclear (6).

Among all behavioral parameters, anxiety is thought to be most sensitive to testosterone and this hormone is either endogenous or exogenous and has been reported to have anxiolytic effect in the elevated plus maze (EPM) test $(7,8)$. In addition, gonadectomy (GDX) results in anxiety-like behavior in male rats and increased exhibition of signs of

\footnotetext{
* Corresponding author: Nayere Askari, Dept of Physiology, Shahid Bahonar University of Kerman, Kerman, Iran

Email: Askari.nr@gmail.com
} 
anxiety in open field test (OFT) and EPM test (8).

The genus Pistacia belongs to the Anacardiaceae family, and the most popular species of pistacia are Pistacia lentiscus, $P$. atlantica Desf., P. terebinthus L., P. vera L., and P. khinjuk Stock. The main habitat of the pistachio species is the Middle East, and three of them occur in Iran; P. vera L., P. khinjuk Stocks., and $P$. atlantica Desf. In traditional medicine, different parts of $P$. atlantica, including resin, bark, and fruit, have been used for their therapeutic effects, such as aphrodisiac activity and treatment of liver, kidney, heart, and respiratory system disorders, and wound healing (9). This plant is rats under chronic stress.

\section{Material and Methods}

$P$. atlantica fruit was obtained from the Jabal Barez Mountain (Kerman, Iran), xylazine from Alfasan International (Woerden, Netherlands), ketamine from Alfasan International (Woerden, Netherlands), and 54 adult male Wistar rats $(250-300 \mathrm{~g})$ from the Animal Center of Shahid Bahonar University of Kerman.

Preparation of the $P$. atlantica extract:

The $P$. atlantica fruits were collected from the mountains of Jabal Barez of Kerman, in August 2014. Then, 400 gr of bane was washed with water, dried away from direct sunlight, and powdered using an electric mill. The resulting powder was dissolved in hydroalcoholic solvent (70 ethanol/30 water) for 48 hours and soaked and stirred using a magnetic stirrer, after which the resulting material was filtered and ethanol was evaporated in a rotary vacuum evaporator (15). Male rats (250-300 g) were obtained from the Animal Center of Shahid Bahonar University of Kerman and were adapted to the laboratory conditions for 2 weeks before the experiments. The animals were randomly divided into 9 groups $(n=6)$ under standard conditions, with a temperature of $25 \pm 1{ }^{\circ} \mathrm{C}$, humidity of $50 \pm$ $10 \%$, and a 12 hour light/12 hour dark cycle. a rich source of terpene and phytosterol. In Algeria, the fruits of $P$. atlantica have been traditionally used to reduce stress $(10,11)$.

Phytosterols and terpenoids are the main components of the root and stem of Eurycoma longifolia (12). E. longifolia exhibited anxiolytic effects in behavioral test such as EPM and OFT similar to Diazepam (13). Bigoniya et al. found that $\mathrm{E}$. thymifolia steroid showed marked anti-stress and anxiolytic effects (14). However, no substantial work has been conducted on the anxiolytic effect of bane. Therefore, the present study has been designed to explore the anxiolytic activity of bane in intact animals and as a source of phytosterol in castrated The rats had free access to food and water. All experiments followed the ethical guidelines for investigation of experimental pain in animals (16). Specific efforts were made to minimize animal suffering and to decrease the number of animals used in accordance with public health service policies.

General experimental procedure: Before the GDX and chronic unpredictable stress (CUS) protocol, the animals were tested in the EPM to determine individual anxiety level. Subsequently, the groups were randomly assigned to one of the following experimental groups:

\section{Intact rat groups include:}

(1) Control (lack of exposure to stress or treatment with drugs)

(2) Daily treatment with saline

(3) Daily treatment with P. atlantica (100 $\mathrm{mg} / \mathrm{kg}, 20$ days)

(4) Daily exposure to CUS (20 days)

(5) Daily exposure to CUS and treatment with

$P$. atlantica $(100 \mathrm{mg} / \mathrm{kg}, 20$ days)

$\mathrm{n}=6$ per group

\section{Gonadectomized rat include:}

(6) GDX (lack of exposure to stress or treatment with drugs)

(7) GDX and daily treatment with $P$. atlantica (100 mg/kg, 20 days).

(8) GDX and daily exposure to CUS (20 days). 
(9) GDX and daily exposure to CUS and treatment with $P$. atlantica $(100 \mathrm{mg} / \mathrm{kg}, 20$ days)

$\mathrm{n}=6$ per group

Rats were bilaterally castrated with ketamine $(90 \mathrm{mg} / \mathrm{kg})$ and xylazine $(10 \mathrm{mg} / \mathrm{kg})$ anesthesia. For operations, the scrotum and the underlying tunica were incised, the vasa deferentia were ligated, and the testes removed. Then, the scrotal wall was closed with sutures and animals were observed daily for signs of infection. Antibiotics were administered as needed. The rats were allowed to recover for 5 weeks, and then, gavaged for
20 days and exposed to CUS. For induction of chronic stress, the Xing Ma method was used with some modifications (17). We used this protocol because it was used as an animal model to induce anxiety. This animal model of stress consists of chronic exposure to variable unpredictable stressors, none of which is sufficient alone to induce long-lasting effects. The stressors used varied and were applied in a different sequence each week to avoid any habituation (Table 1). Each animal was exposed to one stressor per day individually for a period of 20 days.

Table 1: The stressors which was assessed in study

\begin{tabular}{|c|c|c|c|c|c|c|c|c|c|c|}
\hline Day & 1 & 2 & 3 & 4 & 5 & 6 & 7 & 8 & 9 & 10 \\
\hline $\begin{array}{l}\text { Stress } \\
\text { or }\end{array}$ & $\begin{array}{l}\text { Shaking } \\
45 \\
\text { minutes }\end{array}$ & $\begin{array}{c}\text { Cold } \\
\text { swimming } \\
(5 \text { minutes, } \\
\left.10^{\circ} \mathrm{C}\right)\end{array}$ & $\begin{array}{c}\text { Restraint } \\
(1.5 \\
\text { hours })\end{array}$ & $\begin{array}{c}\text { Tail } \\
\text { pinch } \\
(1 \\
\text { minute })\end{array}$ & $\begin{array}{c}\text { Water } \\
\text { deprivation } \\
\text { (24 hours) }\end{array}$ & $\begin{array}{c}\text { Restrai } \\
\text { nt } \\
(1.5 \\
\text { hours })\end{array}$ & $\begin{array}{c}\text { Cold } \\
\text { swimming } \\
(5 \text { minutes } \\
\left.10{ }^{\circ} \mathrm{C}\right)\end{array}$ & $\begin{array}{c}\text { Food } \\
\text { deprivation } \\
(24 \text { hours })\end{array}$ & $\begin{array}{c}\text { Restrai } \\
\text { nt } \\
(1.5 \\
\text { hours })\end{array}$ & $\begin{array}{l}\text { Shaking } \\
\text { (high } \\
\text { speed) }\end{array}$ \\
\hline Day & 11 & 12 & 13 & 14 & 15 & 16 & 17 & 18 & 19 & 20 \\
\hline $\begin{array}{c}\text { Stress } \\
\text { or }\end{array}$ & $\begin{array}{c}\text { Tail } \\
\text { pinch } \\
(1 \\
\text { minute })\end{array}$ & $\begin{array}{c}\text { Water } \\
\text { deprivation } \\
\text { (24 hours) }\end{array}$ & $\begin{array}{c}\text { Social } \\
\text { Isolation } \\
(24 \\
\text { hours })\end{array}$ & $\begin{array}{l}\text { Restraint } \\
\text { ( } 2 \text { hours) }\end{array}$ & $\begin{array}{c}\text { Cold } \\
\text { swimming } \\
10{ }^{\circ} \mathrm{C}(5 \\
\text { minutes })\end{array}$ & $\begin{array}{l}\text { Shakin } \\
\text { g } \\
\text { (High } \\
\text { speed) }\end{array}$ & $\begin{array}{l}\text { Restraint } \\
\text { (1.5 hours) }\end{array}$ & $\begin{array}{c}\text { Tail pinch } \\
\text { (1 minutes) }\end{array}$ & $\begin{array}{c}\text { food } \\
\text { depriva } \\
\text { tion } \\
(24 \\
\text { hours) }\end{array}$ & $\begin{array}{c}\text { social } \\
\text { isolation } \\
(24 \\
\text { hours })\end{array}$ \\
\hline
\end{tabular}

Evaluation of serum levels of testosterone in gonadectomized animals showed testosterone levels decreased approximately to zero level (data not shown).
On day $20 \quad(60$ minutes after oral administration), the rats were subjected to behavioral tests and sacrificed to assess changes in serum testosterone concentrations.

Chronic stress

day 20 behavior test surgery day 35

The EPM test apparatus consists of two open arms $(50 \times 10 \mathrm{~cm})$ and two enclosed arms (50 $\times 10 \times 40 \mathrm{~cm}$ ) opposite each other at $50 \mathrm{~cm}$ above the floor. At the beginning of the test, the rat was placed in the center of the EPM and was then allowed to freely explore for 5 minutes. The testing room was quiet and lit with a dim red light. The number of arms entries and the amount of time spent in the open and closed arms were recorded for statistical analysis (18).
All data were expressed as mean \pm SEM. The significant differences among groups were analyzed using a one-way analysis of variance (ANOVA) followed by Tukey's test.

\section{Results}

There were no significant differences between control and saline groups. Therefore, the data from these two groups were averaged and used as the control group. 
In intact rats, the chronic daily oral gavage with bane $(100 \mathrm{mg} / \mathrm{kg})$ increased the percentage of entries and time spent in the open $\operatorname{arms}(\mathrm{P}<0.050)$ (Figures 1 and 2$)$ compared with the control group.

In intact rats subjected to CUS, there were significant decreases in the percentage of time spent $(\mathrm{P}<0.050)$ (Figure 1) and entries in the open arms $(\mathrm{P}<0.001)$ (Figure 2) compared with the control. However, this decrease was reversed by oral administration of bane through gavage. Thus, there was no difference in the percentage of time spent and entries in the open arms between rats treated with oral gavage of bane subjected to CUS and the control group (Figures 1 and 2).

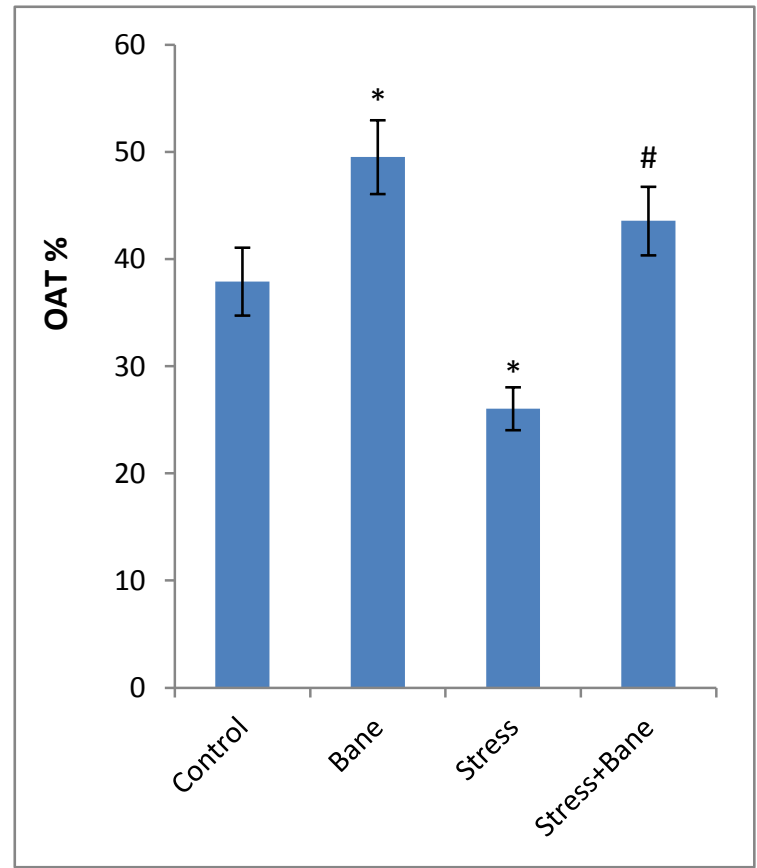

Data are presented as mean \pm SEM for each group of at least 6 rats

$* \mathrm{P}<0.050$ indicates significant differences compared with the control group

\#P $<0.500$ versus. Stress group

Figure 1: Effect of bane and chronic stress on the percentage of time in the open arms of the elevated plus maze in intact rats

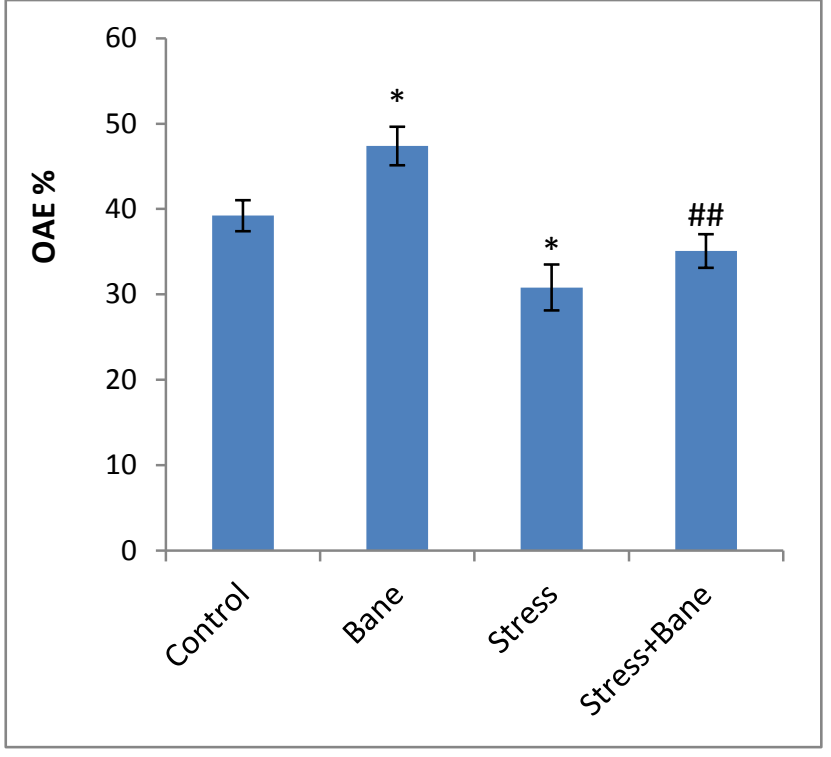

Data are presented as mean \pm SEM for each group of at least 6 rats

$* \mathrm{P}<0.050$ indicates significant differences compared with the control group

\#\#P $<0.010$ vs. Stress group

Figure 2: Effect of bane and chronic stress on the percentage of entries in the open arms of the elevated plus maze in intact rats

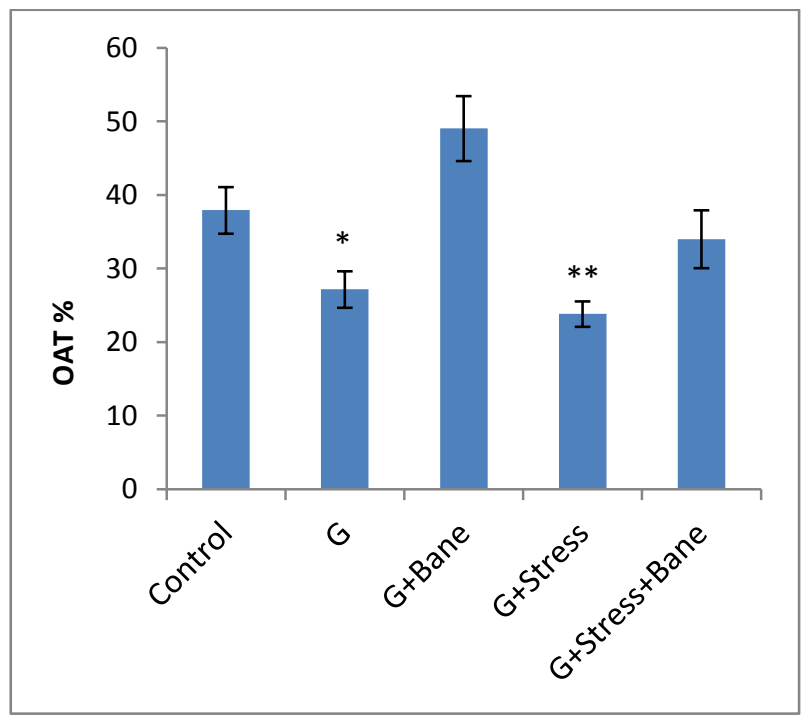

Data are presented as mean \pm SEM for each group of at least 6 rats

$* \mathrm{P}<0.050$ indicates significant differences compared with the control group

$* * \mathrm{P}<0.010$ vs. control group

G: Gonadectomy

Figure 3: Effect of gonadectomy on the percentage of time spent in the open arms of the elevated plus maze 


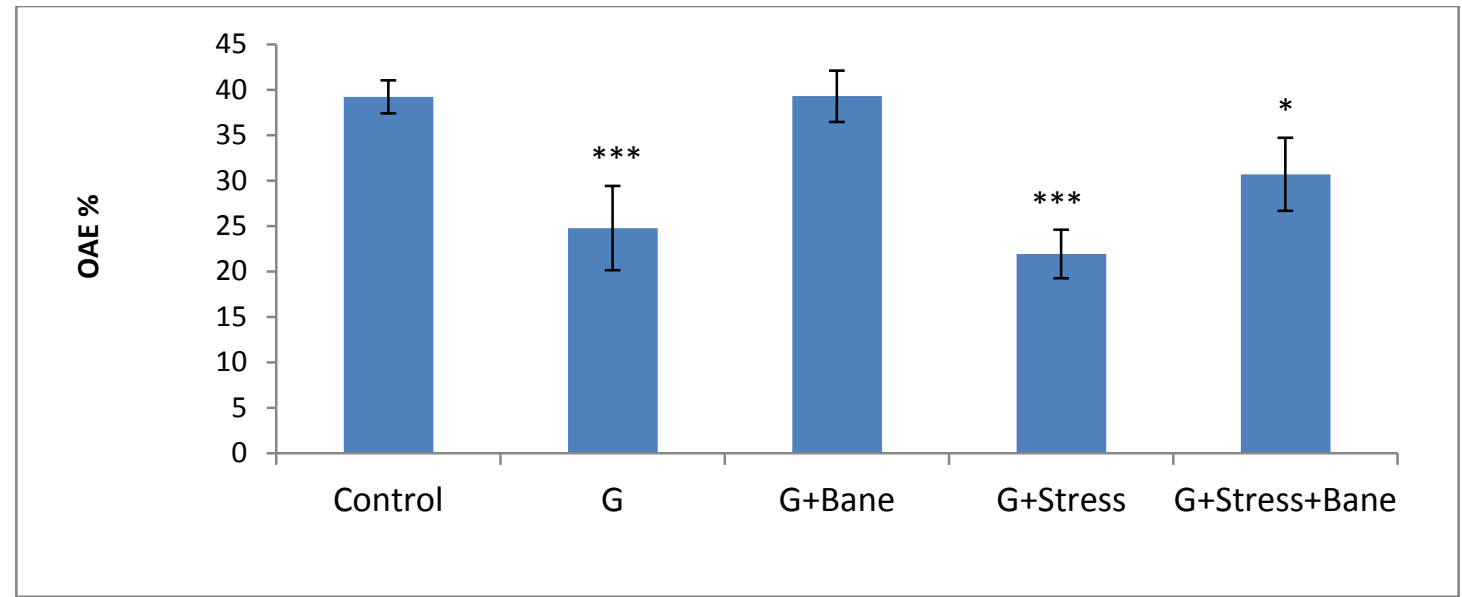

Data are presented as mean \pm SEM for each group of at least 6 rats

$* \mathrm{P}<0.050$ indicates significant differences compared with the control group

$* * * \mathrm{P}<0.001 \mathrm{vs}$. control group

G: Gonadectomy

Figure 4: Effect of gonadectomy on the percentage of entries in the open arms of the elevated plus maze

Animals that were subjected to CUS and received oral gavage of bane showed higher percentages of time spent $(\mathrm{P}<0.050)$ (Figure $1)$ and entries $(\mathrm{P}<0.010)$ (Figure 2$)$ compared with rats subjected to CUS without gavage of bane.

In gonadectomized rats, the percentage of entries $(\mathrm{P}<0.001)$ and time spent in the open arms of the EPM $(\mathrm{P}<0.050)$ decreased compared with the control group (Figures 3 and 4). This decrease was reversed by oral gavage of bane. Thus, chronic daily oral gavage with bane $(100 \mathrm{mg} / \mathrm{kg})$ increased the percentage of time spent $(\mathrm{P}<0.010)$ (Figure 5) and entries $(\mathrm{P}<0.050)$ (Figure 6) in gonadectomized rats that received bane compared with the GDX group.

Gonadectomized animals subjected to CUS showed lower percentage of time spent $(\mathrm{P}<$ 0.010) (Figure 3) and entries $(\mathrm{P}<0.001)$ (Figure 4) compared with the control group.

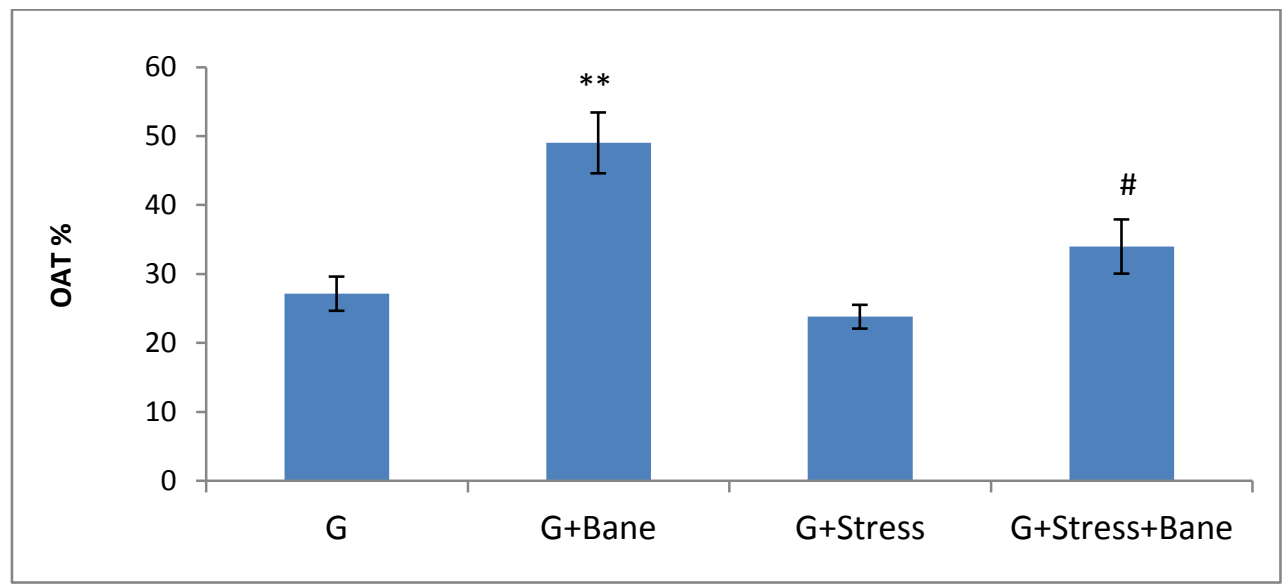

Data are presented as mean \pm SEM for each group of at least 6 rats $* \mathrm{P}<0.050$ indicates significant differences compared with the GDX group \#P $<0.050$ vs. $\mathrm{G}+$ Stress group

G: Gonadectomy

Figure 5: Effect of bane and chronic stress on the percentage of time spent in the open arms of the elevated plus maze in gonadectomized rats 
Gonadectomized rats that were subjected to CUS and received oral gavage of bane showed higher percentage of time spent $(\mathrm{P}<0.050)$
(Figure 5) and entries $(\mathrm{P}<0.050)$ (Figure 6) compared with gonadectomized rats subjected to CUS without oral gavage of bane.

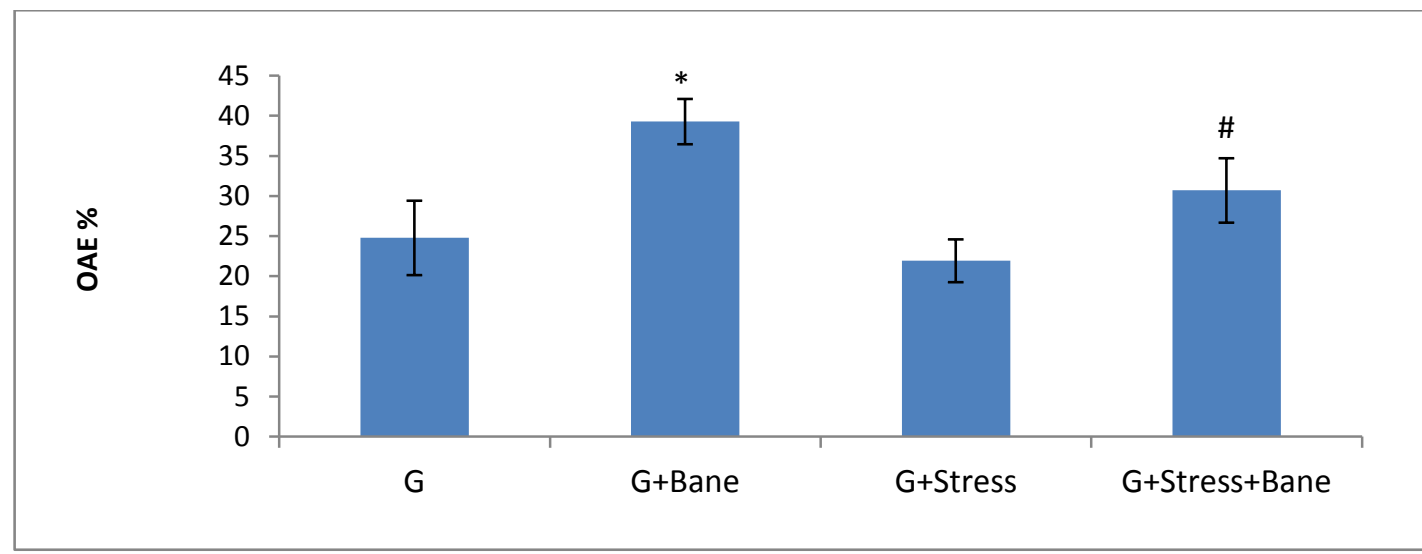

Data are presented as mean \pm SEM for each group of at least 6 rats $* \mathrm{P}<0.050$ indicates significant differences compared with the GDX group $\# \mathrm{P}<0.050$ vs. $\mathrm{G}+$ Stress group G: Gonadectomy

Figure 6: Effect of bane and chronic stress on the percentage of entries in the open arms in the elevated plus maze in gonadectomized rats

\section{Discussion}

Our research demonstrated that $P$. atlantica hydroalcoholic extract has an anxiolytic-like effect on intact and gonadectomized male rats subjected to CUS. The CUS model is similar to the environmental stressors that individuals experience in daily life (19). In this study, we used CUS in gonadectomized rats, as an animal model of andropause, to study the effect of $\mathrm{P}$. atlantica fruit extract.

To the authors' knowledge, it is the first time that the effects of the fruit of bane have been evaluated in an experimental model of anxiety. The results of the present study show that the percentages of entries and time spent in the open arms of the EPM were decreased in rats subjected to CUS, which were significantly reversed by treatment with bane. Therefore, bane appears to have anxiolytic-like effects. Many terpenes are aromatic hydrocarbons, and thus, may have had a protective function (20). Aromatherapy is currently used worldwide in the management of chronic pain, depression, anxiety, some cognitive disorders, insomnia, and stress-related disorders (21). Furthermore $\alpha$-pinene (aromatic compound) has an anxiolytic-like effect; therefore, the inhalation of $\alpha$-pinene for 60 minutes results in a significant increase in the total distance traveled in the EPM test compared with the control group (22).

Gallic acid (3,4,5-trihydroxybenzoic acid) is a phenolic compound. Several studies have indicate the antidepressant-like activity of gallic acid (23). Oil of pistachio species contain abundant fatty acids including oleic, linolenic, palmitic, palmitoleic, stearic, myristic, eicosanoic, behenic, lignoceric, arachidonic, pentadecanoic, hexadecanoic, octadecanoic, and margaric acids (24). Carlos M. Contreras et al. in 2014 demonstrated that a mixture of 8 fatty acids (linoleic, palmitic, stearic, myristic, elaidic, lauric, oleic, and palmitoleic acids) at concentrations similar to human amniotic fluid produces anxiolytic-like effects comparable to diazepam in Wistar rats. This effect is thought to be because of myristic acid. Low testosterone with advancing age is a risk factor for Alzheimer's disease (AD) (25). 
The most abundant sterol reported in fruits of some pistachio species are, respectively, $\beta$ sitosterol, campesterol, avenasterol, stigmasterol, brassicasterol, and cholesterol (26). Incorporation of $\beta$-sitosterol into the membrane increases resistance to oxidative stress and lipid peroxidation thus indicating a considerable effect on neurodegenerative disorders like Alzheimer's disease (27).

The main components of $P$. atlantica fruit extract are monoterpene hydrocarbons such as $\beta$-myrcene (41.4\%), $\alpha$-Pinene $(32.48 \%)$, and limonene $(4.66 \%)$ (28). The essential oil of Cananga odorata contain monoterpene hydrocarbons such as limonene, myrcene, and $\alpha$-Pinene and is used in aromatherapy and is believed to be effective in treating depression, anxiety, and high blood pressure (29). There are sterol compounds in fruits of $P$. vera, $P$. atlantica, $P$. lentiscus, and $P$. terebinthus, respectively, contain $\beta$-sitosterol, campesterol, $\Delta^{5}$-avenasterol, stigmasterol, brassicasterol, and cholesterol $(26,30,31)$. Hence, $P$. atlantica with important components such as terpene and phytosterol restores testosterone level that leads to reduced anxiety.

\section{Conclusion}

Testosterone level in men begins to decline with aging and some emotional difficulties such as anxiety are associated with low testosterone levels. Hormone replacement therapy (HRT) has been shown to be linked to an increased incidence of cancer. P. atlantica is a good source of terpenoids, phenolic compounds, fatty acids, and sterols. In traditional medicine, $P$. atlantica has been used for its aphrodisiac activity. The present study results showed that anxiety-like behavior were significantly reversed by treatment with $P$. atlantica. Thus, it can be concluded that $P$. atlantica, with its critical. components, plays a valuable role in reducing anxiety in the andropause period and even before it.

\section{Acknowledgement}

The authors sincerely thank to Dr. Mansour mirtajaddini; Biology Department; University of Shahid Bahonar Kerman.

Conflict of interests: None declared.

\section{Refrences}

1. Barron AM, Pike CJ. Sex hormones, aging, and Alzheimer's disease. Front Biosci (Elite Ed) 2012; 4:976-97.

2. Barrett-Connor E, Khaw KT, Yen SSC. Endogenous sex hormone levels in older adult men with diabetes mellitus .Am J Epidemiol 1990; 132(5):895-901.

3. Phillips GB, Pinkernell BH, Jing TY. The association of hyperestrogenemia with coronary thrombosis in men. Arterioscler Thromb Vasc Biol 1996; 16(11):1383- 7.

4. Delhez M, Hansenne M, Legros JJ. [Testosterone and depression in men aged over 50 years. Andropause and psychopathology: minimal systemic work-up]. Ann Endocrinol (Paris) 2003; 64(2):162-9.

5. Etkin A, Prater KE, Schatzberg AF, Menon V, Greicius MD. Disrupted amygdalar subregion functional connectivity and evidence of a compensatory network in generalized anxiety disorder. Arch Gen Psychiatry 2009; 66(12):1361-72.

6. van Reedt Dortland AK, Giltay EJ, van Veen T, Zitman FG, Penninx BW. Metabolic syndrome abnormalities are associated with severity of anxiety and depression and with tricyclic antidepressant use. Acta Psychiatr Scand 2010; 122(1):30-9.

7. Aikey JL, Nyby JG, Anmuth DM, James PJ. Testosterone rapidly reduces anxiety in male house mice (Mus musculus). Horm Behav 2002; 42(4):448-60.

8. Edinger KL, Frye CA. Testosterone's analgesic, anxiolytic, and cognitive-enhancing effects may be due in part to actions of its 5alphareduced metabolites in the hippocampus. Behav Neurosci 2004; 118(6):1352-64.

9. Bozorgi M, Memariani Z, Mobli M, Salehi Surmaghi MH, Shams-Ardekani MR, Rahimi R. Five Pistacia species (P. vera, P. atlantica, P. terebinthus, P. khinjuk, and P. lentiscus): a review of their traditional uses, phytochemistry, and pharmacology. Scientific World Journal 2013; 2013:219815. 
10. Mecherara-Idjeri S, Hassani A, Castola V. Composition and chemical variability of the essential oil from Pistacia lentiscus L. growing wild in Algeria part I: leaf oil. Journal of Essential Oil Research 2008; 20(1):32-8.

11. Yousfi M, Nedjmi B, Bellal R, Ben Bertal D, Palla G. Fatty acids and sterols of Pistacia atlantica fruit oil .J Am Oil Chem Soc 2002; 79(10):1049-50.

12. Rahmalia A, Esyanti RR, Iriawati I. A qualitative and quantitative evaluation of terpenoid and alkaloid in root and stem of pasak bumi (eurycoma longifolia Jack). Jurnal Matematika \& Sains 2011; 16(1):49-52.

13. Ang HH, Cheang HS. Studies on the anxiolytic activity of eurycoma longlfolia jack roots in mice. Jap J Pharmacol 1999; 79(4):497-500.

14. Bigoniya, P., B. Sirohi, and A.K. Shukla, CNS Depressant Profile of Euphorbia thymifolia Linn Phytosterol in Mice. 2013.

15. Laghari AQ, Memon Sh, Nelofar A, Laghari AH. Extraction, identification and antioxidative properties of the flavonoid-rich fractions from leaves and flowers of cassia angustifolia. Am J Analyt Chem 2011; 2(8):871-8.

16. Zimmermann M. Ethical guidelines for investigations of experimental pain in conscious animals. Pain 1983; 16(2):109-10.

17. Ma X, Wang R, Zhao X, Zhang C, Sun J, Li J, et al. Antidepressant-like effect of flaxseed secoisolariciresinol diglycoside in ovariectomized mice subjected to unpredictable chronic stress. Metab Brain Dis 2013; 28(1):77-84.

18. Pellow S, Chopin P, File SE, Briley $M$. Validation of open: closed arm entries in an elevated plus-maze as a measure of anxiety in the rat. J Neurosci Methods 1985; 14(3):14967.

19. Garcia R. Stress, metaplasticity, and antidepressants. Curr Mol Med 2002; 2(7):62938.

20. Pichersky E, Noel JP, Dudareva N. Biosynthesis of plant volatiles: nature's diversity and ingenuity. Science 2006. 311(5762):808-11.

21. Perry N, Perry E. Aromatherapy in the management of psychiatric disorders: clinical and neuropharmacological perspectives. CNS Drugs 2006; 20(4):257-80.

22. Kasuya H, Okada N, Kubohara M, Satou T, Masuo Y, Koike K. Expression of BDNF and
TH mRNA in the brain following inhaled administration of $\alpha$-pinene. Phytother Res 2015; 29(1):43-7.

23. Turan N, Can OD, Ozturk Y. Antidepressantlike effects of gallic acid: dual effect on serotonergic and catecholaminergic neurotransmissions. Klinik Psikofarmakol Bülteni 2015; 25(1):S144-5.

24. Satil F, Azcan N, Baser KHC. Fatty acid composition of pistachio nuts in Turkey. Molbank (Chemistry of Natural Compounds) 2003; 39(4):322-4.

25. Rosario ER. Carroll J, Pike CJ. Testosterone regulation of Alzheimer-like neuropathology in male $3 \times \mathrm{Tg}-\mathrm{AD}$ mice involves both estrogen and androgen pathways. Brain Res 2010; 1359:281-90.

26. Arena E, Campisi S, Fallico B, Maccarone E. Distribution of fatty acids and phytosterols as a criterion to discriminate geographic origin of pistachio seeds. Food Chem 2007; 104(1):4038.

27. Shi C, Wu F, Zhu XC, Xu J. Incorporation of bata-sitosterol into the membrane increases resistance to oxidative stress and lipid peroxidation via estrogen receptor-mediated PI3K/GSK3 $\beta$ signaling. Biochim Biophys Acta 2013; 1830(3):2538-44.

28. Mahmoudvand H, Kheirandish F, Ghasemi Kia M, Tavakoli Kareshk A, Yarahmadi M. Chemical composition, protoscolicidal effects and acute toxicity of Pistacia atlantica Desf. fruit extract. Nat Prod Res 2015; 1-4. [Epub ahead of print]

29. Tan LT, Lee LH, Yin WF, Chan CK, Abdul Kadir H, Chan KG, et al. Traditional uses, phytochemistry, and bioactivities of cananga odorata (Ylang-Ylang). Evid Based Complement Alternat Med 2015; 2015:896314.

30. Trabelsi H, Cherif OA, Sakouhi F, Villeneuve $\mathrm{P}$, Renaud J, Barouh $\mathrm{N}$, et al. Total lipid content, fatty acids and 4-desmethylsterols accumulation in developing fruit of Pistacia lentiscus L. growing wild in Tunisia. Food Chem 2012; 131(2):434-40.

31. Charef M, Yousefi M, Saidi M, Stocker P. Determination of the fatty acid composition of acorn (Quercus), Pistacia lentiscus seeds growing in Algeria. J Am Oil Chem Soc 2008; 85(10):921-4. 